\title{
Membaca Opera Batak Lakon Perempuan di Pinggir Danau Produksi Pusat Latihan Opera Batak
}

\author{
Lismade Soraya Juliana Siagian', Nur Sahid, dan Catur Wibono \\ Jurusan Teater, Fakultas Seni Pertunjukan, Institut Seni Indonesia Yogyakarta
}

jurnal tari, teater, dan wayang volume 2 number 2 ,

November 2019

page $74-83$

\begin{abstract}
Opera Batak is one of theatre in Indonesia. This research about dramaturgy of Opera Batak. The Dramaturgy of Opera Batak Perempuan di Pinggir Danau, PLOt production at North Sumatera, begins with understanding the staging of more than understanding a written text by using the theoretical basis of theater dramaturgy by Euginio Barba and research of qualitative methods. This research has been doing for two month at Pematang Siantar, North Sumatera district where Batak Opera originally come from. This research aims to dig about structure and tecstur, and the theatre elements from the performance. Opera Batak PLOt production in the group play Perempuan di Pinggir Danau that the form of theater based on traditional Batak area for the Batak society as a medium of entertainment and messaging truths of life.
\end{abstract}

Keywords: theatre; dramaturgy; Opera Batak

\section{Pendahuluan}

Teater rakyat di Indonesia hidup, berkembang, dan diajarkan secara turun-temurun dari generasi ke generasi. Teater rakyat mempunyai peran penting dalam perkembangan teater di Indonesia. Teater rakyat di Indonesia yang masih bertahan, salah satunya, adalah teater rakyat dari Sumatera Utara yang disebut Opera Batak. Opera Batak didukung masyarakat Batak Toba, Tapanuli Utara, Sumatera Utara. Asal penyebutan Opera Batak ketika orang Belanda masuk ke Pulau Samosir pada awal abad ke-19. Belanda menjuluki teater rakyat Batak dengan nama Opera gaya Batak, atau kemudian dikenal sebagai Opera Batak. Kondisi masyarakat Batak Toba pada waktu itu tidak memiliki seni pertunjukan sekuler, kecuali seni ritual yang menyatu dengan upacara adat (Purba, 2000: 27). Keberadaan teater rakyat Opera Batak pun dipengaruhi oleh keadaan sosial masyarakat pendukungnya.

Pembentukan Opera Batak sejak tahun 1920-an dilakukan oleh Tilhang Oberlin Gultom dengan mendirikan Opera Batak
Tilhang Serindo. Serindo adalah singkatan dari Seni Ragam Indonesia. Opera Batak Tilhang Serindo semakin populer, sebab alat musiknya semakin diperbanyak, sehingga semakin menarik minat penonton. Permasalahan terjadi ketika pemimpin Opera Batak Tilhang Serindo pertama, bernama Tilhang Gultom, meninggal dunia. Opera Batak Tilhang Serindo berhenti mengadakan pementasan. Belum ada generasi yang mampu mempertahankan eksistensi teater rakyat Opera Batak sehingga hampir punah. Perubahan umumnya terjadi seiring perkembangan zaman dan pola pikir masyarakatnya.

Pengembangan Opera Batak dilanjutkan dengan pembentukan Pusat Latihan Opera Batak (PLOt) pada tahun 2005 dalam rangka revitalisasi Opera Batak. Revitalisasi tersebut dilakukan dengan memfasilitasi berbagai kegiatan untuk dinamika pertunjukan lokal dan budaya setempat yang berada di Pematang Siantar, Sumatera Utara. Jadi, kehadiran dan kontribusi Opera Batak PLOt sangat mempengaruhi perkembangan teater rakyat Opera Batak di Sumatera Utara.

\footnotetext{
1 Alamat korespondensi: Institut Seni Indonesia Yogyakarta, Jl. Parangtritis Km. 6,5 Yogyakarta. E-mail: lismadesoraya@gmail.com; HP: 082136582969
} 
Salah satu lakon Opera Batak dengan judul Perempuan di Pinggir Danau, karya Lena Simanjuntak, bersumber pada legenda Danau Toba dan dikaitkan dengan fenomena masa kini. Lakon Perempuan di Pinggir Danau menjadi menarik dengan pembaharuannya mengusung tema perempuan, air, dan lingkungan, dengan latar belakang Danau Toba. Tema tersebut yang menggerakkan terjemahan ke dalam tiga bahasa lainnya, yakni Inggris, Jerman, serta Batak Toba, dan juga ke dalam aksara Batak varian Toba. Pementasan Opera Batak Perempuan di Pinggir Danau dipersiapkan untuk mengingatkan penonton tentang pentingnya menjaga kelestarian Danau Toba sebagai kekayaan alam Indonesia, bahkan dunia.

Ide cerita teater rakyat Opera Batak pada umumnya bersumber pada legenda, mitos, cerita kepahlawanan, cerita rakyat setempat, atau adanya berbagai inovasi dan gagasan baru. Lakon Perempuan di Pinggir Danau karya Lena Simanjuntak bersumber pada legenda Danau Toba, yang dikembangkan dengan menghadirkan kebauan dengan menghadirkan isu-isu fenomena sosial dan ide gerakan ekologis. Seperti wawancara peneliti dengan Lena Simanjuntak, Penulis naskah dan Sutradara lakon Perempuan di Pinggir Danau, di Padepokan Seni Bagong Kussudiarjo, Yogyakarta pada 22 Oktober 2013. Dengan adanya pembaharuan, tentu saja dramaturgi Opera Batak PLOt lakon Perempuan di Pinggir Danau menjadi berbeda dari garapan Opera Batak sebelumnya. Lakon Perempuan di Pinggir Danau memiliki unsur pertunjukan yang dapat dikaji aspek dramaturginya. Oleh sebab itu, penting untuk mengkaji tentang dramaturgi Opera Batak lakon Perempuan di Pinggir Danau, mengingat bahwa sebelumnya belum ada yang mengkaji dramaturgi Opera Batak lakon Perempuan di Pinggir Danau. Oleh sebab itu perlu dikaji keberadaan Opera Batak PLOt di Pematang Siantar, Sumatera Utara, bagaimana unsur-unsurnya sehingga mamu menemukan dramaturgi opera Batak PLOt lakon Perempuan di Pinggir Danau.

Landasan teori dalam penelitian ini menggunakan teori dramaturgi yang ditulis oleh Eugènio Barba pada buku berjudul $A$ Dictionary of Theatre Antropology: The Secret Art of the Performer. Menurut Eugènio Barba, dramaturgi hanya bisa diidentifikasi dari suatu teks tertulis otonom (teks drama) dan proses pertunjukan teater yang melibatkan para karakter (Barba via Nur Sahid, 2012: 15). Maka kajian dramaturgi perlu pemahaman pementasan dan juga pemahaman teks tertulis. Pemahaman terhadap teks tertulis dikaji melalui teori struktur tekstur oleh Kernodle. Pemahaman terhadap pementasan dikaji melalui teori semiotik Tadeusz Kowzan.

Teori struktur tekstur oleh Kernodle mencakup alur, karakter, tema, dialog, mood (musik atau suasana hati), dan spektakel. Pemahaman terhadap pementasan dikaji melalui teori semiotik Tadeusz Kowzan. Teori Tadeusz Kowzan sebenarnya adalah teori tentang semiotika teater meliputi tiga belas sistem tanda, yaitu kata, nada, mimik, gestur, gerak, make up, gaya rambut, kostum, properti, setting, lighting, musik, dan efek suara atau bunyi. Pada penelitian ini Teori Tadeusz Kowzan bukan untuk menganalisis semiotika teater, melainkan digunakan untuk analisis unsur-unsur teater secara detail pada pementasan Opera Batak lakon Perempuan di Pinggir Danau. Dari analisis struktur, tekstur, dan unsur-unsur teater, diperoleh pemahaman terhadap lakon (teks otonom) dan pementasan. Kemudian analisis struktur tekstur dikaitkan dengan unsur-unsur teater, lebih lanjut dapat dikaji bentuk dramaturgi Opera Batak PLOt lakon Perempuan di Pinggir Danau.

Kemudian hasil penelitian ini dilaporkan dengan menggunakan metode kualitatif untuk mendeskripsikan data. Pada penelitian kualitatif pengumpulan data dibedakan menjadi dua, yaitu data primer dan data sekunder. Data primer adalah data yang diperoleh dari sumber pertama yang dilakukan melalui wawancara pada narasumber untuk mendukung penelitian, sementara data sekunder adalah data yang membantu penelitian objek, seperti kepustakaan berupa buku dan jurnal. Tahap pengolahan dan analisis data digambarkan melalui skema 1. 
Pengamatan awal dilakukan terhadap kelompok Opera Batak PLOt dengan langkah (1) mengumpulkan informasi mengenai keberadaan Opera Batak PLOt di Pematang Siantar; langkah (2) dilakukan analisis data terhadap teks lakon Perempuan di Pinggir Danau menggunakan teori Kernodle, di antaranya (a) analisis struktur, yaitu mencakup alur, karakter atau tokoh, dan tema; (b) analisis Tekstur terhadap pementasannya, yaitu mencakup dialog, suasana, dan spektakel.

Langkah (3) dilakukan analisis data terhadap pertunjukan Opera Batak lakon Perempuan di Pinggir Danau. Langkah (4) dilakukan analisis terhadap unsur-unsur teater berdasarkan teori Tadeusz Kowzan, yaitu kata, nada, gestur, gerak, mimik, setting, make up, gaya rambut, kostum, properti, tata cahaya, bunyi, dan musik. Pada langkah (5) dan (6) merupakan analisis secara paralel untuk menentukan dramaturgi Opera Batak lakon Perempuan di Pinggir Danau. Data-data yang telah diperoleh dapat dipilih dan disusun secara sistematis untuk kemudian dianalisis bersama dengan acuan yang ditentukan, sehingga dapat diketahui dramaturgi Opera Batak lakon Perempuan di Pinggir Danau.

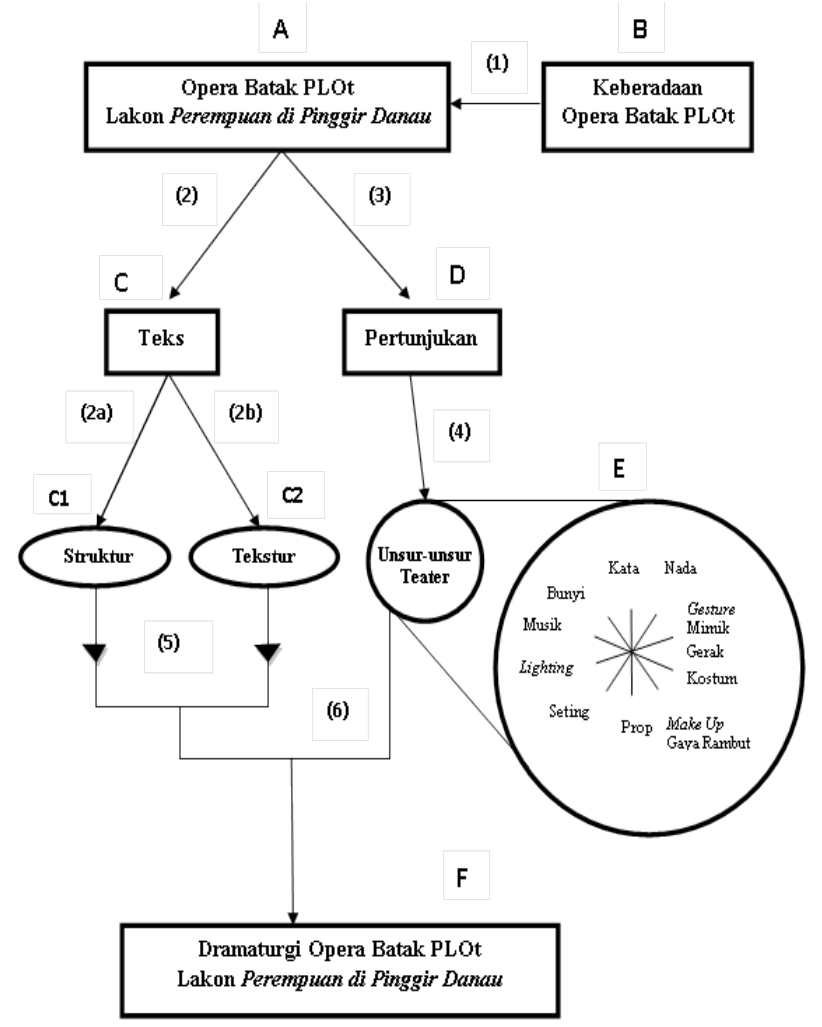

Skema 1. Tahap penelitian. (Skema: Lismade, 2016)

\section{Pembahasan}

Dramaturgi dapat diidentifikasi melalui teks tertulis otonom (teks drama) dan proses pertunjukan teater yang melibatkan para karakter. (Sahid, 2012: 15) Untuk mengetahui dramaturgi Opera Batak lakon Perempuan di Pinggir Danau produksi PLOt, diperlukan pemahaman dahulu tentang struktur dan tekstur, serta unsur-unsur teater pada pertunjukan Opera Batak Perempuan di Pinggir Danau.

Teori struktur dan tekstur Kernodle dibutuhkan untuk mengidentifikasi teks otonom tertulis. Teori Tadeusz Kowzan mengenai tiga belas sistem tanda, digunakan untuk menganalisis unsur-unsur teater secara detail. Penggunaan teori Tadeusz Kowzan bukan untuk menganalisis semiotika teater, melainkan hanya digunakan untuk analisis unsur-unsur teater. Keduanya akan dibahas secara terpisah. Dengan demikian, analisis terhadap dramaturgi Barba pertunjukan lakon Perempuan di Pinggir Danau menjadi lebih detail.

Kernoddle\&Kernoddle (1978: 265) mengatakan bahwa nilai-nilai dramatik karya teater mencakup alur, tokoh, tema, dialog, mood (musik atau suasana hati), dan spektakel. Dari keenam unsur tersebut, ketiga unsur pertama disebut struktur, sedangkan ketiga berikutnya disebut sebagai tektur.

\section{Struktur Lakon Perempuan di Pinggir Danau}

Analisis struktur Kernodle terdiri dari alur, tokoh, dan tema. Alur lakon Perempuan di Pinggir Danau meliputi eksposisi, komplikasi, klimaks, dan antiklimaks, sebab tidak terdapat penyelesaian masalah pada akhir lakon. Eksposisi yang terdapat pada adegan I, adegan II, dan adegan III sebagai pembukaan dari sebuah cerita yang memberikan gambaran, penjelasan, keterangan mengenai masalah, waktu, dan tempat agar dapat dimengerti penonton. Komplikasi, yaitu kerumitan yang membangun konflik pada lakon Perempuan di Pinggir Danau terdapat dalam adegan IV, 
adegan V, adegan VI, adegan VII, adegan VII, adegan VIII, adegan IX, dan adegan X.

Kemudian klimaks atau puncak konflik pada lakon Perempuan di Pinggir Danau terjadi saat pertentangan Ibu Ikan dengan Samosir, Narator, dan ditambah suara-suara penentang. Klimaks pada lakon terdapat pada adegan XV. Pada tahap antiklimaks, konflik mulai mereda dan tidak terdapat penyelesaian masalah. Setelah Ibu Ikan ditangkap dan dibungkam tak dapat berkata-kata, terjadi penurunan laku pada lakon Perempuan di Pinggir Danau. Tahapan alur digambarkan melalui bagan 1 .

Pada Opera Batak lakon Perempuan di Pinggir Danau diawali dengan eksposisi, yakni pelukisan permasalahan; komplikasi, yakni pengenalan peran, motif lakon, pelukisan suasana, kemudian terjadi jalinan kejadian, timbulnya kerumitan semakin tinggi sampai pada peristiwa konflik, mencapai puncak klimaks, dan dilanjutkan dengan antiklimaks, yakni penurunan laku. Pada tahap antiklimaks, konflik mereda dan persoalan menjadi selesai. Bila teori Aristoteles biasanya menggunakan penyelesaian, maka lakon Perempuan di Pinggir Danau diakhiri pada antiklimaks tanpa ada penyelesaian terhadap masalah.

Berdasarkan urutan waktu peristiwanya, lakon Perempuan di Pinggir Danau dikategorikan sebagai alur campuran. Alur campuran merupakan alur yang peristiwanya dimulai dari awal masa sekarang, masa lalu, kembali ke masa sekarang, kemudian masa depan. Lakon Perempuan di Pinggir Danau dimulai dengan penyampaian perempuan tentang pengenalan permasalahan pada masa sekarang, dilanjutkan lakon melalui legenda terjadinya Danau Toba pada masa lampau, kembali ke masa sekarang, pada masa Danau Toba mengalami kerusakan, kemudian menuju masa depan ketika Narator membacakan surat masa depan pada masa manusia kekurangan air.

Karakter dalam drama biasa disebut tokoh, yakni faktor yang paling penting untuk menggerakkan alur. Tokoh yang akan dijelaskan karakterisasinya pada lakon Perempuan di Pinggir Danau adalah Narator, Ibu Ikan (Perempuan), Samosir, Putri Ikan (Sondang Nauli), dan Toba.
1. Narator

Pada lakon Perempuan di Pinggir Danau, Narator berlaku sebagai tokoh pencerita. Tokoh Narator dari segi fisiologis digambarkan sebagai seorang pria setengah baya dan betubuh tegap. Narator memiliki karakter yang humoris dan bijaksana. Narator berlaku sebagai tokoh pembawa alur cerita.

2. Tokoh Samosir

Tokoh Samosir digambarkan sebagai pemuda bertubuh tinggi, tegap, berkulit sawo matang, dan menggunakan pakaian sederhana. Dari segi psikologis memiliki sikap keras, pemarah, tidak sabar, dan ingkar janji. Segi sosiologisnya berstatus sosial menengah ke bawah, hidup sebatang kara sebab keluarganya mati kelaparan. Samosir bekerja sebagai petani. Samosir ialah suami Sondang Nauli dan ayah dari Toba.

\section{Tokoh Putri Ikan}

Tokoh Putri Ikan digambarkan sebagai perempuan muda yang cantik, berkulit sawo matang, dan rambutnya terurai panjang. Putri Ikan adalah jelmaan ikan yang berubah menjadi manusia. Putri Ikan kemudian diberi nama Sondang Nauli dan menjadi istri Samosir serta ibu dari Toba. Sondang Nauli adalah istri yang penuh kasih sayang, setia, rajin, dan terampil. Sondang Nauli menyayangi suami dan anaknya dengan sepenuh hati.

4. Tokoh Toba

Toba adalah anak satu-satunya dari Samosir dan Sondang Nauli. Toba merupakan tokoh pemicu konflik. Toba digambarkan sebagai seorang anak kecil yang bersikap ceroboh dan menyesali

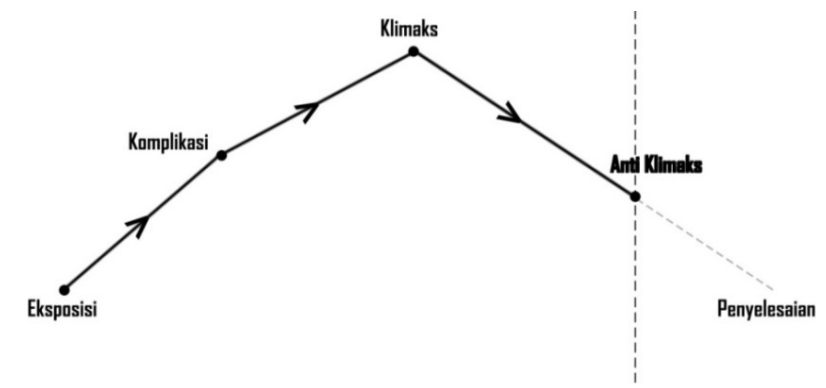

Bagan 1. Bagan tahapan alur lakon Perempuan di Pinggir Danau. (Bagan: Lismade, 2016) 
perbuatanya namun selalu mengulanginya kembali.

5. Tokoh Ibu Ikan (perempuan)

Pada awal lakon Perempuan di Pinggir Danau, tokoh Ibu Ikan dihadirkan sebagai sosok Perempuan yang memperkenalkan masalah pada lakon. Pada kelanjutannya diceritakan bahwa Perempuan di awal sebagai Ibu Ikan, mengutus anaknya untuk menjadi manusia. Ibu Ikan merupakan ibu dari Putri Ikan. Ibu Ikan bersifat lembut, tegas, bijaksana, memiliki keinginan yang tinggi untuk menjaga alam, dan setia terhadap janji.

Tema merupakan jiwa dari keseluruhan isi kerangka cerita dan dapat pula dikatakan sebagai ide utama. Dalam setiap cerita rakyat Batak dalam Opera Batak, temanya sudah jelas dan dapat dimengerti. Tema berupa nilai-nilai kemanusiaan sebagai suatu pesan cerita yang disesuaikan dengan zaman. Peristiwa tersebut terjadi setelah Danau Toba terbentuk. Ketika perjanjian yang dibuat Samosir untuk menjaga Danau Toba tidak dilakukannya, Danau Toba mengalami kerusakan dan merugikan para perempuan di pinggir danau. Tema besar Lakon Perempuan di Pinggir Danau adalah Air, Perempuan, dan Lingkungan Hidup.

Pemahaman terhadap tema berkaitan dengan pemahaman terhadap alur, permasalahan dalam cerita, dan penokohan. Berdasarkan hal tersebut dapat ditarik kesimpulan bahwa tema dirumuskan dalam sebuah kalimat, "Perkembangan zaman dapat merusak lingkungan apabila tidak dijaga demi kepentingan umat manusia di masa depan."

\section{Tekstur Pertunjukan Lakon Perempuan di Pinggir Danau}

Tekstur pertunjukan terdiri dari dialog, mood (musik atau suasana hati), dan spektakel. Pertunjukan Opera Batak mementingkan dialog, bahasa, penggunaan diksi dan intonasi, tinggi rendahnya suara, serta tempo dalam berdialog. Ritme dan tempo dialog mempengaruhi munculnya gaya dialog atau yang biasa disebut dengan dialek. Pada lakon Perempuan di Pinggir Danau, dialog menggunakan bahasa Indonesia. Namun, pada penerapannya, tokoh menggunakan bahasa Indonesia dengan dialek Batak Toba ataupun bahasa Batak Toba. Pemain berdialog dengan pengucapan aksentuasi dialog yang wajar, seperti kebiasaan orang Batak berbicara sehari-hari. Penyampaian dialog menggunakan artikulasi yang baik, intonasi keras, dan tempo cepat.

Suasana pada sebuah pertunjukan akan terbentuk ketika nilai dramatik antara dialog dan spektakel dipadukan. Jadi, suasana sangat bergantung pada dialog, suara musik, dan spek takel yang ada dalam cerita. Spektakel pada pertunjukan dipengaruhi oleh pergantian cahaya. Pergantian cahaya dapat mempengaruhi suasana pada pertunjukan. Namun, pada lakon Perempuan di Pinggir Danau, cahaya hanya berfungsi menerangi dan tidak mempengaruhi suasana sehingga suara musik memiliki peranan dominan dalam mempengaruhi suasana lakon Perempuan di Pinggir Danau.

Instrumen musik yang khas digunakan pada pertunjukan Opera Batak adalah ansambel Gondang Sabangunan dan ansambel Gondang Hasapi. Fungsi dan kegunaan kedua ansambel tersebut pada dasarnya sama, yakni semua gondang atau lagu yang dimainkan dalam ansambel Gondang Sabangunan juga dimainkan dalam ansambel Gondang Hasapi. Gondang diartikan sebagai instrumen musik, juga dapat diartikan komposisi lagu, sedangkan kata margondang dapat berarti mengadakan upacara yang memakai ansambel Gondang Sabangunan. (Purba, 2000: 39) Musik berfungsi sebagai penanda suasana, pergantian adegan, serta pengiring nyanyian dan tarian.

Spektakel pada pertunjukan lakon Perempuan di Pinggir Danau didukung oleh unsur kostum dan permainan aktor. Spektakel terdapat pada saat Samosir sedang memancing. Tokoh Putri Ikan memasuki panggung dengan cara menggelinding dari arah belakang panggung menuju ke tengah panggung. Penggunaan kostum sekaligus gerakan aktor mempengaruhi spektakel pada adegan XI saat bencana terjadinya Danau Toba. Gerakan aktor mengibaskan kain ke segala 
arah, memunculkan spektakel. Selain itu, juga menghadirkan tari Tor-tor Sipitu Cawan dan Gerak Silat Mossak.

\section{Unsur-Unsur Teater Lakon Perempuan di Pinggir Danau}

Kajian unsur-unsur teater dibutuhkan untuk mengetahui seluruh unsur pertunjukan lakon Perempuan di Pinggir Danau secara detail. Menurut Tadeusz Kowzan, terdapat tiga belas unsur yang mendukung pertunjukan teater, yaitu kata, nada, mime, gestur, gerak, make up, gaya rambut, kostum, properti, setting, lighting, musik, dan efek suara. Kemudian ketigabelas unsur tersebut dikaitkan berdasarkan analisis struktur tekstur dan unsur-unsur teater. Analisis dramaturgi Opera Batak lakon Perempuan di Pinggir Danau menunjukkan adanya pengembangan pada tekstur pementasannya. Struktur dan tekstur, menurut Kernodle, mencakup alur, karakter, tema, dialog, suasana, dan spektakel. Unsur-unsur teater, menurut Keir Elam, dibagi menjadi kata, nada, gestur, gerak, mimik, properti, seting, kostum, musik, bunyi, tata cahaya, tata rias, dan gaya rambut. Struktur dan tekstur akan dianalisis kaitannya dengan unsur teater untuk mengetahui dramaturgi lakon Perempuan di Pinggir Danau secara detail.

Alur pada lakon Perempuan di Pinggir Danau terdiri dari eksposisi, komplikasi, klimaks, dan antiklimaks. Berdasarkan urutan waktu peristiwanya termasuk alur campuran, berakhir pada antiklimaks tanpa ada penyelesaian masalah. Unsur-unsur teater yang mendukung terbentuknya alur sebagai berikut. Kata dan nada disampaikan melalui dialog, berfungsi menyampaikan informasi tentang adegan sehingga memiliki pengaruh terhadap alur lakon. Contohnya, penyampaian dialog oleh Narator yang memberi penjelasan mengenai alur lakon dari awal hingga akhir. Seting mempengaruhi alur, seperti penggunaan slide proyektor setelah adegan bencana, untuk memperkuat visual Danau Toba.

Karakter didukung oleh unsur teater sebagai berikut. Kata disampaikan melalui dialog berbahasa Batak Toba ataupun bahasa Indonesia. Nada tinggi dan intonasi keras mencerminkan dialek Batak Toba. Mimik dan gestur sesuai dengan suasana peristiwa atau karakterisasi tokoh. Gerakan- gerakan aktor melingkupi gerakan yang realistis sesuai dengan peristiwa, gerakan yang membangun dramatik, dan gerakan yang ditarikan. Gerak yang ditarikan merupakan gerak menggunakan kaidah gerak tari Tortor. Kostum menggunakan bahan dasar ulos sebagai pakaian khas Batak. Beberapa properti
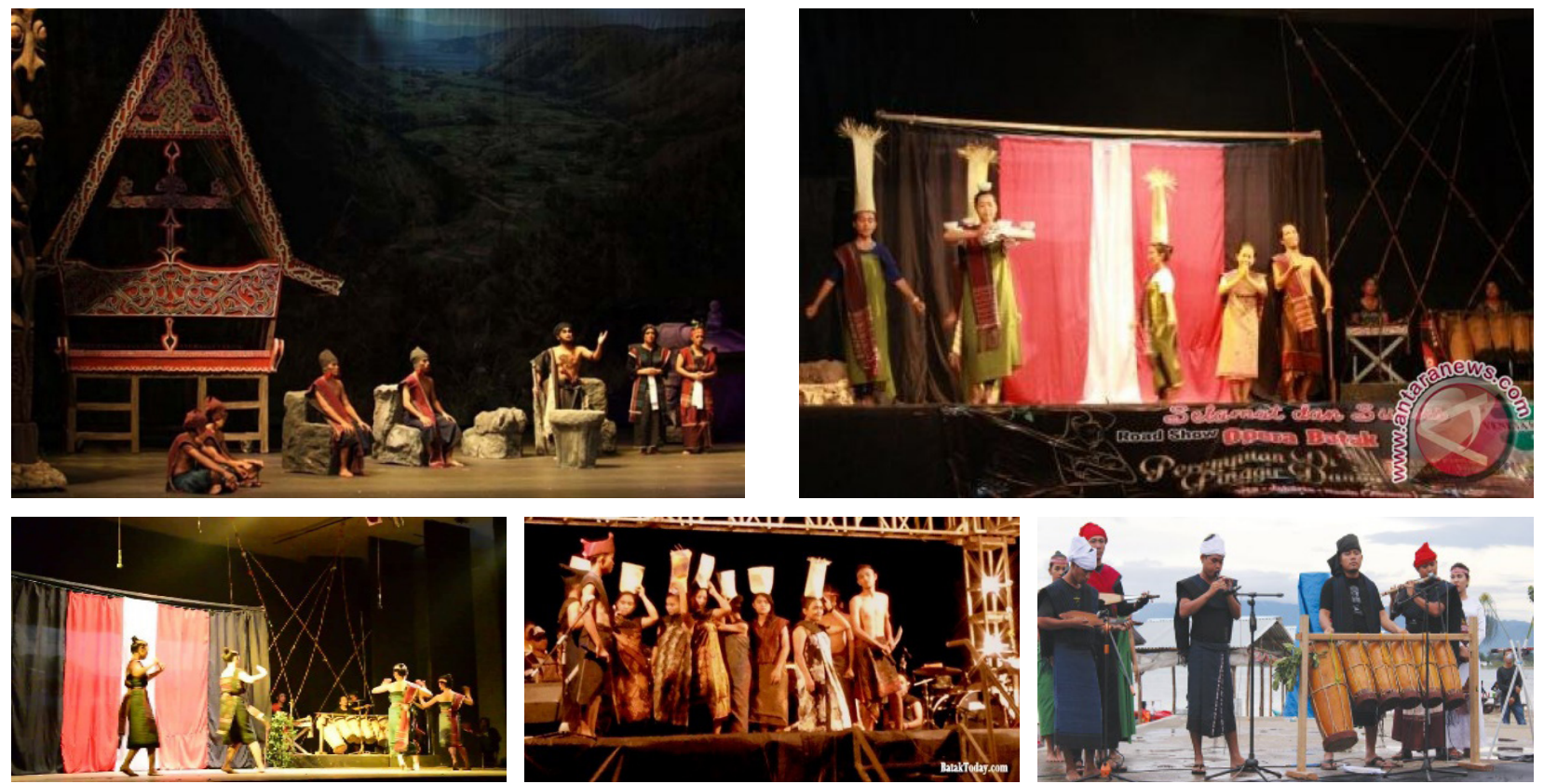

Gambar 1. Pertunjukan Opera Batak Toba dengan lakon Perempuan di Pinggir Danau.

(Sumber: cabiklunik.blogspot.com dan bataktoday.com) 
digunakan oleh aktor sesuai dengan kebutuhan adegan, seperti penggunaan properti kayu, pipa, kain, dan cawan untuk properti tarian. Tata rias dan gaya rambut yang digunakan cukup sederhana sehingga terkesan natural. Tema lakon Perempuan di Pinggir Danau didukung oleh unsur teater, yaitu penyampaian kata-kata dari perjanjian antara Ibu Ikan dan Putri Ikan. Secara keseluruhan lakon dan pementasan, tema dapat disimpulkan dengan kalimat "Perkembangan zaman dapat merusak lingkungan apabila tidak dijaga demi kepentingan umat manusia."

Dialog didukung oleh kata atau bahasa yang digunakan adalah bahasa Batak atau bahasa Indonesia dengan dialek Batak. Contohnya, kata Lae merupakan bahasa Batak yang berarti panggilan untuk ipar lakilaki. Nada yang digunakan adalah nada yang cenderung tinggi dan keras, mencerminkan dialek Batak. Suasana lakon Perempuan di Pinggir Danau berkaitan dengan budaya Batak. Suasana dipengaruhi oleh unsur musik atau nyanyian secara dominan. Untuk menghadirkan suasana cenderung dihadirkan musik atau nyanyian berbahasa Batak yang berkaitan dengan adegan. Spektakel lakon Perempuan di Pinggir Danau dipengaruhi oleh unsur gerak dan kostum. Spektakel pada peristiwa bencana alam disajikan dengan gerakan aktor dan penari yang mengibaskan kain hitam ke segala arah. Tata cahaya tidak mempengaruhi adanya spektakel. Spektakel dengan penggunaan kostum saat Putri Ikan berubah menjadi manusia, spektakel tarian Tor-tor Si Pitu Cawan dan gerak silat Mossak.

\section{Dramaturgi Opera Batak Lakon Perempuan di Pinggir Danau}

Penulis mengamati pertunjukan Perempuan di Pinggir Danau di tempat aslinya, yaitu di pinggiran danau Toba. Kemudian penulis menghadirkannya kembali melalui pertunjukan dengan judul yang sama namun di tempat yang berbeda, yaitu di stage teater Jurusan Teater ISI Yogyakarta. Pertunjukan dianalisis berdasarkan teks dan urutan pengadeganan pada lakon Perempuan di Pinggir Danau dibagi menjadi pembukaan, perkenalan karakter, pertikaian/konflik, tarian hiburan, klimaks, dan antiklimaks.

Tabel 1. Urutan pengadegan pada lakon Perempuan di Pinggir Danau.

\begin{tabular}{|c|c|c|c|}
\hline Urutan & Lakon & Visual & Pementasan \\
\hline Pembukaan & $\begin{array}{l}\text { Musik gondang (gondang } \\
\text { Batak) pembukaan diselingi } \\
\text { suara air. Muncul perempuan } \\
\text { meratap (dengan gaya } \\
\text { andung Batak) sambil } \\
\text { manortor (menari) keadaan } \\
\text { alam. }\end{array}$ & & $\begin{array}{l}\text { Musik gondang pembuka, muncul } \\
\text { Perempuan sambil manortor. Lalu } \\
\text { masuk penari dengan tarian Tor- } \\
\text { tor Saniang Naga Laut. }\end{array}$ \\
\hline $\begin{array}{l}\text { Perkenalan } \\
\text { karakter }\end{array}$ & $\begin{array}{l}\text { Eksposisi, yaitu perkenalan } \\
\text { karakter, kemudian } \\
\text { komplikasi, yakni jalinan } \\
\text { kejadian. Setiap karakter } \\
\text { memiliki peran dalam } \\
\text { membangun dramatik. }\end{array}$ & & $\begin{array}{l}\text { Dialog menggunakan bahasa Batak } \\
\text { Toba dan bahasa Indonesia de- } \\
\text { ngan penyampaian dialek Batak } \\
\text { Toba. Suasana didukung oleh } \\
\text { dialog dan musik atau nyanyian. } \\
\text { Spektakel didukung oleh unsur } \\
\text { kostum, permainan aktor. Spek- } \\
\text { takel menghadirkan tari Cawan } \\
\text { dan gerak silat Mossak. }\end{array}$ \\
\hline
\end{tabular}


Konflik

Tarian hiburan

Klimaks dan anti-klimaks

Penutup
Kerumitan dimulai dengan kehadiran tokoh Toba sebagai pemicu konflik. Konflik pada peristiwa pelanggaran janji Samosir kepada Sondang Nauli.
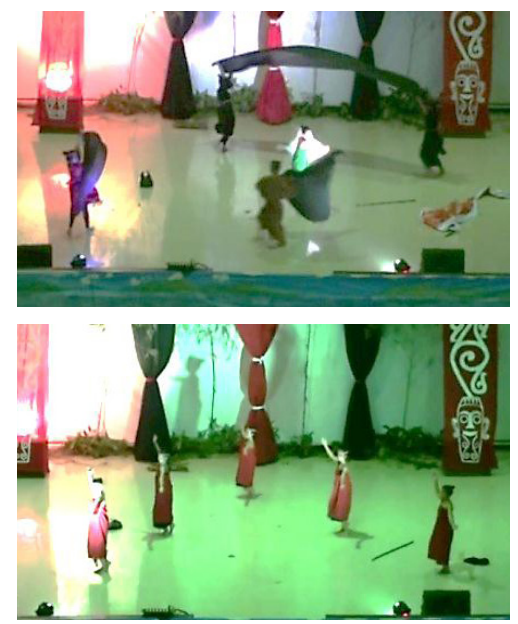

Konflik yang memuncak menuju klimaks. "Perempuan mencoba melepaskan diri dari tangan-tangan yang mencoba menangkapnya".



Kemudian Antiklimaks atau penurunan laku. Narator membacakan surat dari masa depan.

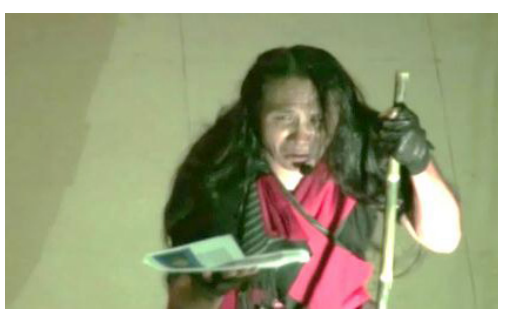

Monolog Narator.
Kehadiran tokoh Toba dijelaskan oleh Narator. Konflik dimulai dengan kemarahan Samosir pada Toba. Kemudian konflik menghadirkan spektakel pada peristiwa bencana alam. Terjadinya Danau Toba disajikan nyanyian 0 Tao Toba.

Menyajikan tarian Tor-tor Lima Puak sebagai reportoar khusus.

Suasana menyedihkan pada bagian klimaks disajikan dengan nyanyian Mardalan Ahu.

Narator membacakan surat dari masa depan dengan gaya monolog. Karakter yang ditampilkan berbeda dari sebelumnya, yaitu gaya rambut yang terurai panjang dan gaya akting seolah-olah sudah tua dengan penampilan tidak terawat.

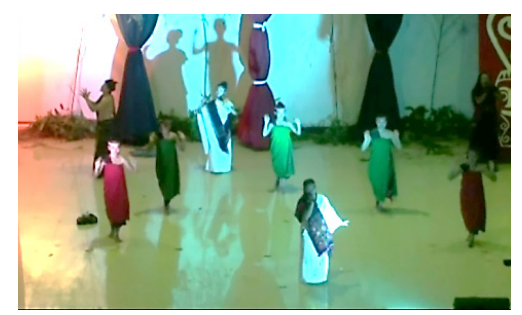

Tarian Tor-tor kreasi. Penari dan semua pemain masuk panggung. Diakhiri dengan teriakan "Horas" tiga kali.
Pada naskah Perempuan di Pinggir Danau peristiwa terus berlanjut. Namun, pada pertunjukannya disajikan reportoar tarian hiburan yang tidak memiliki kaitan dengan lakon. Tarian hiburan yang disajikan adalah tari Tor-tor Lima Puak, yaitu tarian kreasi dengan dasar gerak Tor-tor dari lima subsuku, yakni Toba, Simalungun, Karo, Pak-pak, dan Mandailing.

Tarian Tor-tor merupakan repertoar tersendiri yang disajikan pada pertengahan pertunjukan. Terdapat lima penari yang menggunakan kostum seragam kain berwarna merah. Setelah tarian hiburan, pementasan lakon dilanjutkan kembali. Tarian hiburan disajikan selama tiga menit, tepat setelah adegan $\mathrm{X}$ dan sebelum adegan IX.
Analisis dramaturgi Opera Batak lakon Perempuan di Pinggir Danau menunjukkan adanya pengembangan pada pementasannya. Formula dramaturgi Opera Batak lakon Perempuan di Pinggir Danau digambarkan melalui bagan 2 .

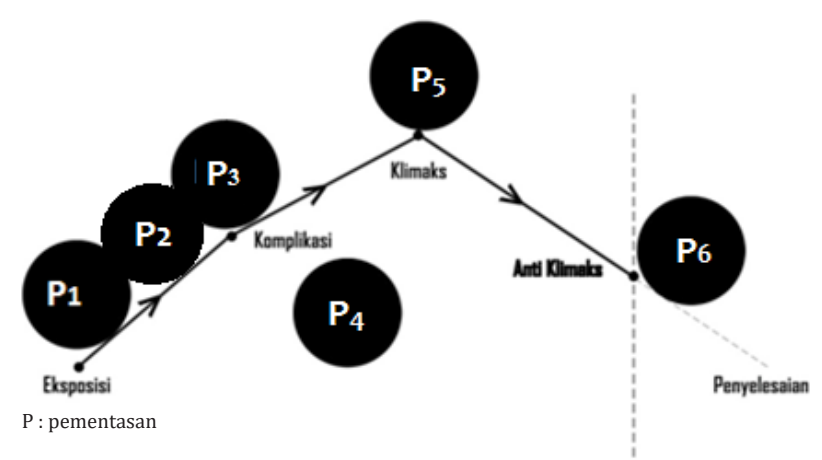

Bagan 2. Formula dramaturgi opera Batak lakon Perempuan di Pinggir Danau. (Bagan: Lismade, 2016) 
Bagan tersebut menunjukkan bahwa tahapan sesuai dengan alur lakon dan urutan pengadeganan. Diawali dengan (P1) Pembuka, (P2) Perkenalan Karakter, (P3) Konflik, (P4) Tarian Hiburan sebagai reportoar khusus yang tidak termasuk lakon, (P5) Klimaks, Antiklimaks, dan (P6) Penutup. Jadi, dramaturgi Opera Batak lakon Perempuan di Pinggir Danau mengalami pengembangan pada pementasannya, lakon tidak mengacu sepenuhnya terhadap naskah sebab dapat dibentuk bervariasi pada pementasannya.

\section{Penutup}

Berdasarkan uraian di atas, dapat diketahui bahwa teater rakyat Opera Batak menyajikan suatu pertunjukan variatif yang berisi pesan moral bersumber cerita rakyat, dan menyampaikan nilai-nilai kearifan lokal masyarakatnya. Opera Batak disebut sebagai teater rakyat karena pengaruh keadaan sosial yang terjadi pada masyarakat. Secara khusus, lakon Perempuan di Pinggir Danau dikaji dengan menggunakan teori dramaturgi Eugenio Barba.

Struktur pertunjukan Opera Batak lakon Perempuan di Pinggir Danau disimpulkan sebagai berikut. Lakon bertema Air, Lingkungan, dan Perempuan. Alur drama berakhir pada antiklimaks atau penurunan laku tanpa ada penyelesaian terhadap masalah. Berdasarkan urutan waktu peristiwanya, lakon Perempuan di Pinggir Danau dapat dikategorikan sebagai alur campuran. Setiap karakter memiliki peranan masing-masing untuk membentuk alur pertunjukan.

Tekstur pada Opera Batak lakon Perempuan di Pinggir Danau, yaitu dialog, suasana, dan spektakel, berkaitan dengan budaya Batak dan membangun dramatik pada pertunjukan. Unsur-unsur pertunjukan teater Opera Batak mengacu pada semua elemen pertunjukannya dan telah dikaji secara detail. Struktur dan tekstur, serta unsur-unsur pertunjukan teater saling berkaitan untuk membangun dramatik. Dengan demikian, dapat diketahui formula dramaturgi Opera Batak lakon Perempuan di Pinggir Danau sebagai berikut. Diawali dengan
(P1) Pembuka, (P2) Perkenalan Karakter, (P3) Konflik, (P4) Tarian Hiburan sebagai reportoar khusus dan tidak termasuk dalam lakon, (P5) Klimaks dan Antiklimaks, serta (P6) Penutup. Opera Batak lakon Perempuan di Pinggir Danau merupakan pertunjukan variatif yang bersumber legenda Danau Toba yang dikembangkan dengan fenomena alam masa kini. Unsur tarian, musik, ataupun lakon tidak selalu terkait satu sama lain sehingga analisis dramaturgi Opera Batak lakon Perempuan di Pinggir Danau mengalami pengembangan dan dapat disesuaikan sesuai dengan kebutuhan pertunjukan serta kemampuan pemain.

Berdasarkan penelitian terhadap Opera Batak lakon Perempuan di Pinggir Danau, PLOt telah mampu menjaga eksistensinya dan mengadakan pementasan hingga ke mancanegara. Apabila diamati, keberlangsungan Opera Batak PLOt patutnya lebih diapresiasi oleh masyarakat Sumatera Utara sebagai pendukung utamanya. Untuk mendukung hal tersebut, pembangunan Gedung Opera Batak diharapkan dapat segera terwujud sebagai fasilitas utama bagi masyarakat dalam mengapresiasi pertunjukan Opera Batak.

\section{Kepustakaan}

Ahmad, A. Kasim. 2006. Mengenal Teater Tradisional di Indonesia. Jakarta: Dewan Kesenian Jakarta.

Azwar, Saifuddin. 2005. Metode Penelitian. Yogyakarta: Pustaka Pelajar.

Bandem, I Made dan Sal Murgiyanto. 1996. Teater Daerah Indonesia. Yogyakarta: Kanisius.

Barba, Eugenio. 1995. Dramaturgy Actions at Works dalam Euginio Barba \& Nicola Savarese. A Dictionary of Theatre Antropology: The ScretArt of the performer. London: Routledge.

Dewojati, Cahyaningrum. 2012. Drama: Sejarah, Teori, dan penerapannya. Yogyakarta: Javakarsa Media.

Hamzah, A. Adjib. 1985. Pengantar Bermain Drama. Bandung: CV. Rosda RD.

Harimawan, RMA. 1986. Dramaturgi. Bandung: PT. Remaja Rosdakarya. 
Kayam, Umar. 1981. Seni, Tradisi, Masyarakat. Jakarta: Sinar Harapan.

Kernodle, George dan Portia Kernodle. 1978. Invitation to the Theatre. New York: Harcout Brace Javanovic.

Moleong, Lexy. 2010. Metodologi Penelitian Kualitatif. Bandung: PT Remaja Rosdakarya.

Nainggolan, Sari. 1991. Skripsi Opera Batak Tilhang Serindo Masyarakat Batak Toba. Yogyakarta: Institut Seni Indonesia.

Purba, Krismus. 2000. Opera Batak Tilhang Serindo: Pengikat Budaya Masyarakat Batak Toba di Jakarta. Yogyakarta: Kalika.

Purwanto, Lephen. 2013. Journal of Dramaturgy Part 1. Yogyakarta: Asosiasi Dramaturgi Indonesia.

Sagala, Jayanti. 2014. Tesis Eksistensi Perempuan dalam Opera Batak Studi Kasus Zulkaidah Harahap. Yogyakarta: Universitas Gajah Mada.

Satoto, Soediro. 2012. Analisis Drama dan Teater. Yogyakarta : Ombak.

Sahid, Nur. 2012. Dramaturgi Teater Gandrik dalam lakon Orde Tabung: Sebuah Kajian Estetika Morfologi dan Paradoks. Yogyakarta: Institut Seni Indonesia. . 2012. Semiotika Teater Teori dan Penerapannya. Yogyakarta: Badan Penerbit ISI Yogyakarta.
Sibarani, Sadar. 2006. Raja Batak. Jakarta: Partano Bato.

Simanjuntak, Lena. 2013. Opera Batak Perempuan di Pinggir Danau. Yogyakarta: Kata Kita.

Strauss, Anselm \& Juliet Corbin. 2009. Dasardasar Penelitian Kualitatif. Yogyakarta: Pustaka Pelajar.

Sumardjo, Jakob. 1992. Perkembangan Teater Modern dan Sastra Drama Indonesia. Bandung: PT. Citra Aditya Bakti.

Watson, Ian. 1983. Towards a Third Theatre. London: Routledge.

Yoeti, Oka A. 1985. Melestarikan Seni Budaya Tradisi yang Nyaris Punah. Yogyakarta: Departemen Pendidikan \& Kebudayaan.

Yudiaryani, 2002. Panggung Teater Dunia, Perkembangan dan Perubahan Konvensi. Yogyakarta: Pustaka Gondho Suli.

\section{Informan}

Thompson Hutasoit, 48 tahun, Kepala Tim Artistik PLOt, Sekretariat PLOt Jalan Bahbolon No. 9 Parluasan, Siantar, Sumatera Utara.

Lena Simanjuntak, 59 tahun, Penulis naskah dan Sutradara Lakon Perempuan di Pinggir Danau, Padepokan Seni Bagong Kussudiarjo, Yogyakarta. 